\title{
Chemoport Management
}

\section{케모포트의 관리법}

Department of Surgery, The Catholic University of Korea, Seoul, Korea

Yo-Han Park, MD., Jin-Kwon Lee, MD., Shinn-Young Kim, MD., Won-Kyung Kang, MD.

가톨릭대학교 의과대학 외과학교실 박요한, 이진권, 김신영, 강원경

\section{초 록}

악성종양의 빈도가 증가하면서 동반된 항암제 사용의 증가로 인 해 반복적이면서 장기간 사용할 수 있는 안전한 정맥경로 확보가 필요하게 되었다. 이에 중심정맥을 통해 비교적 안정적으로 약물 을 공급할 수 있는 케모포트(chemoport)의 사용이 증가하게 되 었고, 사용빈도가 늘어나면서 관련된 부작용 또한 증가되어 관찰 되고 있다. 중심정맥에 도관을 삽입을 한다는 침습적인 시술과 관련한 위험도 있겠지만, 발생되는 부작용 중에는 올바르지 못한 사용 및 관리로 인해 발생하는 부작용이 적지 않으며 이는 케모 포트에 대한 정확한 사용 및 관리방법을 제대로 이해하지 못하였 기 때문이다. 이런 문제점을 최소화하기 위해 케모포트에 대한 올바른 이해와 사용방법에 대해 알아보고 의료진에게 참고가 되 었으면 하고, 이를 토대로 시술을 받은 환자에 대한 교육을 강화 해 올바른 케모포트 사용을 알리는 계기다 되었으면 한다.

\section{서 론}

항암치료 때마다 반복해서 정맥주사를 위한 별도의 혈관 확보가 필요한 암환자에게 중심정맥관(Central venous catheter)을 삽 입하여 항암제, 항생제, 혈액성분 등의 정맥주사를 투여하는 방 법은 환자나 의료진 모두에게 유용하며 종합 비경구영양법 (TPN), 혈액채취에도 사용할 수 있다는 장점을 가지고 있다.

중심정맥관은 삽입하는 술식에 따라 쇄골하정맥 또는 경정맥을 통하여 삽입하는 방법과, 팔에 있는 정맥(Basillic vein or

\section{책임저자 : 강원경}

137-701, 서울시 서초구 반포4동 505번지 가톨릭대학교 서울성모병원 외과 Tel: 02-2258-6104 Fax: 02-2-595-2822 E-mail: wonkkang@catholic.ac.kr 접수일 : 2011년 5월 23일 ; 게재승인일 : 2011년 6월 20일

본 논문의 요지는 2011년 대한임상종양학회 연수강좌에서 발표되었음. cephalic vein)을 통하여 삽입하는 방법으로 구분되며 종류로는 히크만카테터(Hickman catheter), 센트라실(Centrasil), 케모포 트, 대정맥을 이용하는 인트라실(Intrasil) 등이 있다.(1) 히크만카테터와 케모포트 등은 대개 수술실에서 외과의사에 의 해 국소마취 하에 시술되며, 나머지는 병실에서도 시행할 수 있 다. 삽입하는 방식은 카테터마다 차이가 있지만 일단 삽입된 카 테터의 관리는 카테터의 종류에 관계없이 동일하다. 시행을 받은 후 별도의 추가적인 시술이 필요 없이 장기간 사용할 수 있고 퇴 원 후에도 계속해서 사용할 수 있어 많이 사용되고 있는 케모포 트에 대해 적절한 사용 및 관리방법에 대하여 알아보고자 한다.

\section{본 론}

\section{I. 케모포트의 개론}

케모포트는 손이나 발 등의 말초정맥으로 투여할 경우 부작용이 발생할 수 있는 약물 (항암제, 고농도 영양제 등)을 장기간 사용 해야 할 때나 퇴원 후에도 집에서 계속 수액치료나 항생제 치료 가 필요할 경우, 중심정맥관을 통해 삽입되어 안정된 통로를 제 공한다.

수액을 연결할 때를 제외하고는 몸 밖으로 노출되어 있는 관이 없기 때문에 미용적인 효과가 있으며 감염률이 낮다. 하지만 삽 입 당시에나 수액 주입 때 적절하지 못한 조작으로 인해 감염이 나, 혈전형성, 공기 색전 등의 합병증이 발생할 수 있으므로 유의 하여 관리하여야 한다.

\section{II. 삽입}

케모포트는 포트(port)와 카테터(catheter)로 이루어져 있으며 포트는 흥부전벽 또는 액와부 피하에 삽입되고 카테터는 삽입될 정맥까지 터널링을 시행한 피하를 지나서 정맥 내로 삽입된다. 
카테터 끝의 위치는 우심방 위 $2 \mathrm{~cm}$ 정도의 상대정맥(SVC) 말단 에 위치하는 것이 좋으며 포트는 피부 밑 $0.5 \sim 2 \mathrm{~cm}$ 정도 깊이에 포켓을 만들어 삽입하게 된다. ${ }^{(2,3)}$ 이 때 포트가 너무 깊이 위치하 면 촉지가 어려울 수 있으며 포켓에 고정을 시켜 움직이지 않도 록 고정한다. 고정이 확실하지 않은 경우 포트가 뒤집히거나 움 직이는 합병증이 생기니 주의하여야 한다.

중심정맥에 대한 접근이 어려운 경우에는 초음파와 같은 영상장 비를 사용해서 설치하는 것이 유용하다. 케모포트를 삽입할 때에 는 수술실에서 무균적 상태에서 하여야 한다.

\section{III. 관리와 유지}

\section{1. 케모포트 바늘 삽입}

케모포트 바늘은 일직선 바늘(non-coring needle, huberneedle)로 격막이 찢어지거나 새지 않고 통과할 수 있게 만들어 진 바늘이다.(Fig. 1) 바늘을 찌르기 전에 손을 반드시 씻고, 소독 장갑을 착용한다. 포트 주변 반경 $5 \mathrm{~cm}$ 정도를 $2 \%$ chlorhexidine-based preparation으로 소독하기를 권장하며 povidone이나 $70 \%$ alcohol을 사용할 수도 있으며 소독액이 마 르기를 기다린 후 바늘을 찌르게 된다. Povidone 경우에는 적어 도 2 분이 지난 후에 삽입해야 소독 효과가 있다. 바늘에 있는 공 기가 들어가지 않도록 찌르기 전에 생리식염수를 통과 시킨 후 주사기는 그대로 꽂아둔다. 바늘을 찌른 후에는 주사기를 당겨 혈액을 흡인하여 개방성을 확인한 후 생리식염수로 세정한다.

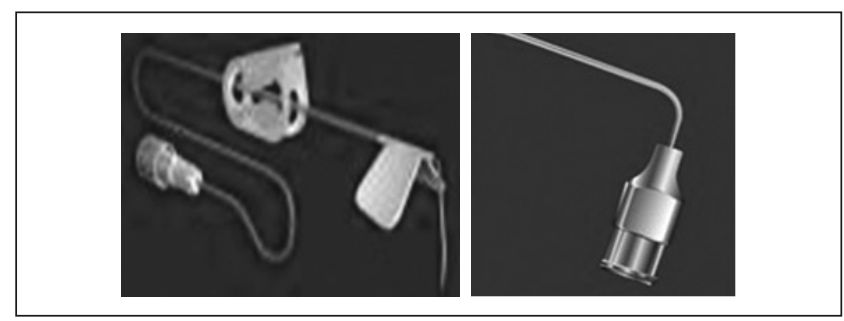

Fig. 1.

\section{2. 드레싱 관리(Dressing Management)}

바늘을 찌른 후에는 소독 거즈(sterile gauze)나 투명, 반투과막 드레싱(transparent, semipermeable dressing)으로 덮는다. 일 반적으로 드레싱은 2-7일에 한 번씩 교환하는데 거즈로 드레싱 한 경우는 2 일에 한 번, 필름 제재인 경우는 적어도 5-7일에 한 번 갈아줘야 하며, 젖거나, 떨어져 나오거나, 오염되었을 경우에 는 교체해야 한다. 땀이 많거나 분비물이 많은 경우에는 거즈를 사용하는 것이 좋다. 바늘의 경우는 일주일 이상은 사용하지 않
는 것이 좋다. 드레싱의 목적은 삽입부위를 깨끗하고 건조하게 유지하는 것이다. 바늘 삽입부위에는 진균감염(fungal infection)이나 내성균을 조장할 수 있기 때문에 국소 항생제 연 고(topical antibiotic ointment)는 사용하지 않는다. 케모포트를 사용하지 않을 경우에는 특별히 소독을 할 필요는 없다.

3. 수액주입 및 바늘교환(Infusion and needle change) 지속적으로 약물이나 수액을 주입 중일 때에는 바늘은 적어도 2 주에 1회 교환하게 되며 환자나 케모포트 상태에 따라 더 앞당겨 서 하기도 한다. 바늘을 제거할 때는 헤파린 희석액을 (1:100) $5 \mathrm{cc}$ 주입하고 클램프를 잠근 후 시행한다. 헤파린 희석액은 케모포트 를 사용하지 않을 때 혈액이 역 주입되면서 혈전을 생성하는 것 을 방지해준다. 또한 혈전이 안 생기게 하기 위해서는 카테터 안 에 혈액이 없어야 하는데 생리식염수로 세정(flushing)하는 것이 필요하다. 특히 채혈(blood sampling) 후에는 케모포트 안에 남 아 있는 혈액이 응고되어 막히지 않도록 $20 \mathrm{ml}$ 의 생리식염수로 세정하고 헤파린을 채워 넣는다.

\section{IV. 합병증}

케모포트를 시행하는 경우, 여러 합병증을 관찰할 수 있으며 (Table 1.) 주요 합병증은 다음과 같다. ${ }^{(4,5)}$

Table 1. 케모포트와 관련된 합병증

\begin{tabular}{l}
\hline 시술과 관련된 합병증 \\
\hline 카테터 혈전증 \\
정맥 혈전증 \\
기흉 \\
누수 \\
통증 \\
카테터 파열 및 공기색전 \\
카테터와 포트 분리 \\
피부괴사 \\
카테터 기능이상 \\
\hline 감염관련 합병증 \\
카테터 관련 감염 \\
혈류 관련 감염 \\
포트삽입부 감염 \\
\hline
\end{tabular}

\section{1. 감염}

케모포트 관리에서 감염을 방지하기 위해 가장 중요한 것은 무균 적으로 모든 시술을 시행하는 것이다. 피부 소독제(Skin 
antisepsis), 포트 삽입부 드레싱(sterile site dressing)과 적절한 손위생(hand hygiene)이 필요하다. 포트 주변을 잘 관찰하는 것 도 중요한데 삽입 부위의 발적이나 통증, 고름이나 진물 등이 있 는지 잘 살펴봐야 한다. 또한 환자가 전신적으로 열이 나거나 오 한 등을 호소하는 지도 잘 봐야 한다.

포트 감염이 확인되었을 경우에는 제거 여부에 대하여 먼저 결정 하여야 한다. 환자 상태가 중증 패혈증(severe sepsis), 화농성 혈 전정맥염(suppurative thrombophlebitis), 심내막염 (endocarditis)을 보이거나, 항생제 치료한 지 72시간 후에도 지 속적으로 혈액 내 감염이 있는 경우에는 케모포트를 제거하도록 한다. 그렇지 않고 합병증이 동반되지 않은 경우에는 포트를 보 존하려고 시도해 볼 수 있다. 혈액 배양 후 경험적으로 2 세대 세 팔로스포린계 항생제를 1 5 mg/mL를 heparin 50 100 U 과 혼합한 뒤 카테터를 채워 넣고 포트를 쓰지 않는다. 이것을 antibiotic lock therapy라고 하며 이 때 전신적 항생제 치료 (systemic antibiotics)를 병행한다. 혈액 배양결과에서 그람 음 성균이나 진균이 배양되는 경우에는 포트를 제거하는 것이 좋으 며, 그람 양성균일 경우에는 감수성 있는 항생제를 사용하여 치 료한다. 항생제 투여 후 증상이 호전되면 계속 치료 하고 72 시간 후 다시 혈액배양을 시행하고 지속적으로 균 감염이 발견된다면 그 때는 포트를 제거한다.

\section{2. 혈전}

혈전으로 인한 카테터 폐색을 막기 위해선 카테터 안에 혈액이 없어야 한다. 세정과 heparin으로 lock하여 혈액이 역류하는 것 을 방지해야 한다. 또한 카테터로 인한 정맥혈전증(venous thrombosis)도 생길 수 있는데 특히 이상 위치(malposition) 시 에 위험도가 증가하며 카테터의 끝의 위치가 상대정맥(SVC) 위 에 있는 것 보다는 상대정맥 아래 쪽에 위치하는 것이 혈전 생성 이 적다고 보고되고 있다.(Fig 1.) 혈관에 따라서도 위험도가 달 라질 수 있으며 오른쪽보다는 왼쪽에, 경정맥(jugular vein)보다 는 쇄골하정맥(subclavian vein)에 삽입하였을 경우, 혈전생성 가능성이 더 높다고 한다. 또한 카테터 감염이 혈전을 더 조장할 수 있어 감염관리에 신경 써야 한다. 예방적으로 항응고제를 사 용하는 것은 큰 의미가 없으나 혈전발생의 가능성이 높은 위험군 에서는 혈전발생을 감소시킬 수 있다고 보고되고 있다. ${ }^{(6,7)}$ 카테터 폐색이 발생하였을 때, 대처방법은 표에 정리하였다.(Table 2.) 혹시 케모포트로 영양수액 투여 후 폐색되었을 경우에는 Bicarbonate를 이용하여 폐색을 해결할 수도 있다.
3. 기타

감염, 혈전 외에 공기 색전이나 약물의 혈관 외 유출, 포트의 손 상 등의 합병증이 생길 수 있다. 공기 색전 방지를 위해서는 공기 가 주입되지 않도록 바늘 삽입이나 수액 주입 시 주의 해야 한다. 환자가 호흡곤란이나 청색증, 빈맥, 저혈압 등을 보일 수 있으며 더 이상 공기가 주입되지 않도록 수액을 즉시 잠그고 환자를 왼 쪽 측와위로 눕히고 머리를 낮추어 주며 산소를 공급한다.

바늘이 비정상적으로 삽입되었을 경우 약물 유출이 생길 수 있 다. 특히 항암제의 경우에는 혈관외 유출(extravasation)으로 인 한 피부 손상을 일으킬 수 있어 주의해야 한다. 바늘이 격막 (septum)을 관통하지 않는 경우나 느슨하게 되었을 경우에 일어 날 수 있어 삽입 위치와 깊이를 잘 확인하고 잘 고정되도록 하여 야 한다.

포트의 손상은 드물지만 삽입 시 카테터가 손상된다거나 삽입 후 사용 도중 바늘을 여러 번 꽂으면서 격막이 찢어지면서 발생할 수 있다. 또한 포트가 피부 아래에서 뒤집히는 경우가 있는데 포 트를 심을 때, 근막(fascia)에 봉합을 안 하거나 한 곳만 봉합을 하였을 경우 발생할 수 있다. 이런 경우를 방지하지 위해 수술 시 2 개 이상의 봉합을 비흡수성 봉합사로 시행하도록 한다.

또한 케모포트 제거 시에도 일부 부속이 파손되어 남거나 카테터

Table 2. 케모포트 폐색 시 대처방법

1. Urokinase $2,500-20,000 \mathrm{U} / \mathrm{mL}$ 의 농도로 희석하여 사용한다

2. Clamp를 풀고 천천히 그리고 부드럽게 urokinase를 locking 한다.

3. 30 60분간 기다린다.

4. Aspiration이 되면 clot 제거 후 $5 \mathrm{cc}$ 의 blood를 채쥐해서 버 린다.

5. 20cc normal saline으로 flushing한다.

6. Line을 연결하거나 안 쓰면 heparin 또는 urokinase로 locking해 놓는다.

Table 3. 케모포트를 시술 받은 환자의 주의사항

다음의 항목 중 관찰되는 상황이 있는 경우 의료진이 진료가 필요하다.

1. 삽입부위의 감염(빨개지거나, 붓거나, 아프거나, 냄새가 나거나,

혹은 분비물이 있을 때)

2. 38도 이상의 열이 있을 때.

3. 카테터가 막힌 경우.

4. 히크만 카테터의 데크론 커프가 피부 밖으로 나온 경우.

5. 카테터가 빠진 경우.

6. 카테터가 찢어지거나 구멍이 난 경우. 
의 일부가 끊어져 체내에 남는 수가 있으니 제거 후에도 케모포 트의 부속물이 다 나 왔는지 확인하거나 흥부 단순 촬영을 시행 하여 확인하는 것도 도움이 된다.

환자들에게 문제상황 발생 시에 의료진에게 알려 적절한 조치를 받도록 교육하여야 하며 환자들이 숙지 해야 할 주의사항은 표와 같다. ${ }^{\left({ }^{8}\right)}$ (Table 3.)

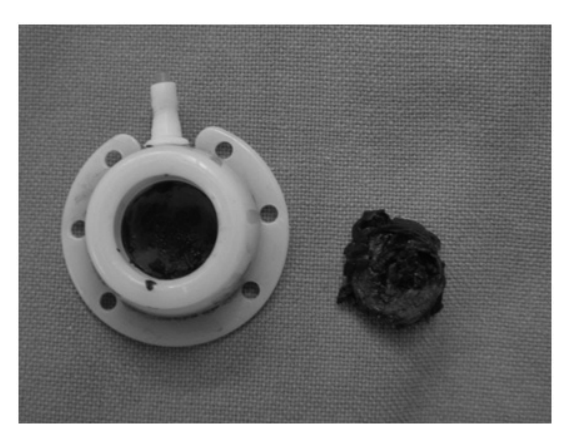

Fig. 2. Removed chemoport due to thrombosis

\section{결 론}

케모포트의 설치, 사용이나 관리의 부주의로 합병증이 많이 발생 하고 있으며 이런 합병증은 환자에게 치명적인 결과를 초래하기 도 한다. 이런 합병증을 줄이기 위해서 가장 중요한 것은 의료진 과 환자에게 교육과 훈련을 통하여 숙련되게 하여 조기에 대처하 는 것이다.

\section{REFERENCES}

1. Clin Trans| Oncol. 2006 Oct;8(10):735-41.Protocol for the implantation of a venous access device (Port-A-Cath System). The complications and solutions found in 560 cases.

Yeste Sánchez L, Galbis Caravajal JM, Fuster Diana CA, Moledo Eiras E.

2. Am J Surg. 1999 Jul;178(1):38-41. Silicone venous access devices positioned with their tips high in the superior vena cava are more likely to malfunction, Petersen J, Delaney JH, Brakstad MT, Rowbotham RK, Bagley CM Jr.

3. Radiology. 2001 Sep;220(3):655-60. Catheter-related upper extremity deep venous thrombosis in cancer patients: a prospective study based on Doppler US. Luciani A, Clement O, Halimi P, Goudot D, Portier F, Bassot V, Luciani JA, Avan P, Frija G, Bonfils $P$.

4. Clin Radiol. 2004 Apr;59(4):349-55. To clot or not to clot? That is the question in central venous catheters. Cadman A, Lawrance JA, Fitzsimmons L, Spencer-Shaw A, Swindell R.

5. Ann Surg Oncol. 2011 Feb;18(2):468-71. Epub 2010 Sep 29. Central venous port placement: a comparison of axillary versus anterior chest wall placement. Pardo I, Rager EL, Bowling MW, Fajardo A, Clare S, Goulet R Jr.

6. Clin Transl Oncol. 2006 Oct;8(10):735-41. Protocol for the implantation of a venous access device (Port-A-Cath System). The complications and solutions found in 560 cases.

Yeste Sánchez L, Galbis Caravajal JM, Fuster Diana CA, Moledo Eiras E. 7. Ann Pharmacother. 2007 Apr;41(4):635-41. Epub 2007 Mar 13. Systemic anticoagulant prophylaxis for central catheter-associated venous thrombosis in cancer patients. Chan A, lannucci A, Dager WE.

8. 대한종양간호학회. 종양간호 실무지침: 항암화학요법편. 2008:xii-xvii 